\title{
Dialogue 7: The role of South-South and triangular co- operation in contexts beyond ODA
}

Cooperation beyond ODA overcomes traditional role concepts in development politics. The conventional ascriptions of the North providing and the South receiving assistance are being contested and increasingly replaced by new modalities that enable countries to engage with each other on a more equal footing. The Second UN High-level Conference on South-South Cooperation (BAPA +40), held in March 2019 in Buenos Aires, empowered the Global South and consolidated South-South cooperation as a key element of the 2030 Agenda. At the same time, triangular cooperation between northern and southern countries is gaining momentum and starting to trigger ministries and implementing agencies to rethink the role of former donors in a setting beyond ODA.

With our discussants we debate the current prospects and challenges for South-South and triangular cooperation and set them in relation to ODA graduation. Are these modes suitable alternatives for graduating countries, especially regarding their demand for technical cooperation and knowledge exchange? How can South-South and triangular cooperation be further promoted, more recognised and improved?

The discussion was held between Orria Goni Delzangles, Team Leader for South-South Cooperation and Finance for Development at the UNDP Africa Finance Sector Hub, Nadine Piefer-Söyler, Policy Analyst for triangular cooperation and cooperation with Latin American and Caribbean countries at the OECD's Development Cooperation Directorate, Martín Rivero Illa:, Coordinator of South-South Cooperation at the Ibero-American General Secretariat, SEGIB $^{119}$, and Rita Walraf, desk officer for emerging countries and triangular cooperation at the Federal Ministry for Economic Cooperation and Development, BMZ. It was facilitated by Christof Kersting, director of the Regional Fund for Triangular Cooperation in Latin America and the Caribbean at GIZ, and Juliane Kolsdorf, editor of this publication. ${ }^{120}$

119 SEGIB is an international support organisation for the Ibero-American community, covering the 19 Spanish- and Portuguese-speaking countries in Latin America and those of the Iberian Peninsula, Spain, Portugal and Andorra.

120 For better distinction from the discussants, the inputs and questions by the facilitators are displayed in italic without naming the respective person. 
Martin, you bring in not only your experience from SEGIB, but also from your previous job as head of the Uruguayan development cooperation agency. What is your opinion about the current prospects and the challenges for South-South and triangular cooperation?

Martín Rivero: First, I would like to differentiate between South-South and triangular cooperation. They are related but they are not the same and this is a point that we consider quite important. There is a lot of noise nowadays about the potential of triangular cooperation. A lot of things are happening, but it is not clear if it is a type of cooperation that will grow constantly in the near future. It seems that it will happen, but it is not yet very clear.

The figures related to triangular cooperation in our region are quite stable in absolute terms, around 120,130 projects every year. But it is changing in its characteristics; it is changing regarding the countries that are involved. To begin with, mainly the countries that were being phased out of traditional ODA from the beginning of this century were participating in triangular cooperation. Chile is a clear example of that. These countries started to develop strategies regarding triangular cooperation in order to maintain their presence in the business of cooperation in the region, and they were quite active about that. Other countries, like Argentina or Mexico and later Uruguay, also started to grow in these terms. They pursued the strategy of being active in the context of development cooperation, but not only for that reason; there is a mix of strategies in each country. Another change regarding triangular cooperation are the areas of engagement. To begin with, those areas were mostly generated by the North, by the traditional donor partner in the relationship, but then this started to change. Health, agriculture or the environment are areas that are more active nowadays in projects of triangular cooperation. The third change is that, in addition to a long history of actors, particularly Germany and Japan, being active in the region, other countries have started increasing their projects of triangular cooperation, like Spain or the United States in Central America in the last seven or eight years, or countries like Luxembourg in the last two to four years. The last change is that while the number of projects has remained relatively stable, the projects are growing in size. At first, there were many small projects or activities, and now there has been a growing number of bigger projects or programmes.

So, the process of triangular cooperation is changing inside, for many different reasons. These reasons have to do with the international context, with national strategies and also with a learning process among the countries from the North or the traditional donors, or the global cooperation institutions that are starting to see the capacities and the potential of triangular cooperation. 
Orria, could you confirm this process of change from an African viewpoint? What are your views on the prospects and challenges of trilateral and SouthSouth cooperation?

Orria Goni: In broader terms, that is the trend. But, before looking into the SDGs and South-South Cooperation, we need to look into the Addis Ababa Action Agenda; more precisely the implications of the $3^{\text {rd }}$ Financing for Development Agenda which looks at the practical means of how to achieve the SDGs. We need to see how these means of implementation have impacted on the way countries are starting to look into their own domestic resource mobilisation agenda, tapping into the public and private financing, internally and externally, with its different layers and chapters.

This is also influencing how African countries are looking into their foreign affairs agendas to boost South-South and triangular partnerships that support their national development priorities. In this regard, there has been increased ownership in the south-south partnership building, including a self-empowering approach, where African countries have realized that they are not only receiving technical support, but that they can be active South-South sharing countries, as they have a wide range of development solutions ready to share. Graduating MIC countries like Botswana or Cabo Verde realise that they have a lot to sell and to export as good practices and are setting up their own development agencies to do so. But also, least developed countries like Rwanda, which envision graduating from ODA by 2030 or 2050 , are currently boosting and setting up their national architecture for SSC. This is the 'decade of action', and I believe this is the African decade, where African countries are empowering themselves and getting ready to have a leading role in the global development agenda.

In UNDP's renewed strategy we want to focus on prioritizing "African money for African development". As such, we are providing support to countries in assessing what countries are doing well, what good practices they have and what can be shared through SSC with our peers. This Pan-African approach on SSC aims at transforming the development cooperation in Africa and widening the vision of what SSC is. It means suggesting that SSC is beyond the cooperation support provided by key African partners, such as China, India and Brazil. In this regard, it is positive to note that such partnership agreements are being formalized at the continental level through the Africa Union (AU) - as the case of the FOCAC ${ }^{121}$ with China, for example - with the intention to foster broader alignment with continental priorities, including the AU's Agenda 2063.

In the case of Africa, engagements between countries have been very much limited to South-South cooperation. I have still not seen a triangular cooperation agenda; in fact, I am looking forward to partnering with all of you to see

121 Forum on China-Africa Cooperation. 
that happen. This should be a coherent continental set-up, with the AU's Agenda 2063 and the SDGs, including the AU Development Agency, AUDANEPAD, having the greatest influence. A potential triangular cooperation partner is Japan, where the Tokyo International Conference of African Development (TICAD) could serve as a good means of reinforcing $\mathrm{TrC}$ in Africa.

Nadine, within the OECD, you work more on a macro level. What do you think are the prospects and challenges for South-South and triangular cooperation? Nadine Piefer-Söyler: At the OECD, we see an increased interest in the topic of triangular cooperation and, of course, BAPA +40 was very instrumental in that. I would say it was really a milestone event, also from the perspective of the Development Assistance Committee (DAC). In the beginning, when we at the OECD Secretariat started putting the topic of preparing for BAPA+40 and triangular cooperation on the agenda for official DAC meetings, it was not very prominent. Then BAPA +40 happened and there was good participation, also from the DAC, in the meeting and afterwards. The DAC members are more aware of the importance of triangular cooperation, of the discussions that are happening, and they are looking for ways of using the modality more.

Discussing triangular cooperation in the context of ODA graduation as a milestone of transition is very good, but only one way of using the modality and only in a certain context. We are trying to really mainstream triangular cooperation into the normal toolkit or set of instruments of all development partners, so that when you start thinking about a cooperation project, you automatically think about the option of doing it trilaterally or at least including a triangular component.

We also set ourselves the mission of pulling triangular cooperation out of its perceived niche of just being an instrument for Latin America and the Caribbean (LAC) or for middle-income countries. There are a couple of myths going around, and this is one of them. Everyone agrees that triangular cooperation is one of the cooperation modalities in LAC, but it is not yet mainstreamed in Africa or Asia. Several countries have agencies or other institutional structures in place to engage in South-South and triangular co-operation and they have a large network of partners in their regions and beyond.

I think, from a longer-term view, we can see different regional prospects on triangular cooperation. There are different stages of how well the instrument is developed and included in normal cooperation methodologies. For example, we see training approaches in partnership with institutions from Asia, the MENA region and Africa. To give an example, Japan is working with organisations that have specific expertise in a certain area, such as rice production. Through previous bilateral cooperation these organisations or institutions are strengthened and they can become pivotal partners to train participants from other countries in Africa and Asia. We also see that approach in Latin America and the 
Caribbean, but there, like Martin was saying, most triangular initiatives have developed more into a partnership-oriented approach over the years.

And that is where we see huge potential. We need to work more in partnerships to achieve the 2030 Agenda and to move beyond the binary donor-recipient model - I really see triangular cooperation as a good way to forge those partnerships.

The challenge here is that we need a mindset shift for that to happen. And it is not only the mindset that is important, but also the internal institutional regulations, the way we engage in cooperation. Whenever we talk about triangular cooperation, we often hear that the transaction costs are so high, that it is more complicated to engage in triangular initiatives. But that comes with us being geared towards the default option of working bilaterally or in regional cooperation. The latter usually means to work with a regional organisation that then coordinates among countries in that region. As the call for more multi-stakeholder partnerships with different actors beyond governments gets louder, I see this as the big opportunity for triangular cooperation and other innovative partnership-oriented modalities to shape the future of development cooperation. We will need to change the way we work to be able to better engage in these types of horizontal partnerships and also accept that everyone learns and provides resources at the same time - thus, enshrining mutual learning as a key element of development partnerships.

Rita, what do you think about the current prospects and challenges, reflecting your involvement with South-South and triangular cooperation from the side of German development policy? Maybe you can also share some insights from the recent evaluation of triangular cooperation conducted by the German Institute for Development Evaluation, DEval?

Rita Walraf: First of all, I would like to focus on the challenges that we face within German development cooperation in terms of triangular cooperation. Although Germany figures among the most active bilateral DAC donors in that area, to many of my colleagues, triangular cooperation seems to be a tiny modality and is often not supposed to be really useful for broad, big and effective development cooperation. I think this is due to several reasons that have already been mentioned by Nadine and others. First, people always put the issue of high transaction costs onto the agenda. They say it is too complicated to start such a modality; it requires too much investment in terms of coordination, talking and dealing with at least three partners at the same time. Then, many tell me that it is just a modality that works in Latin America and the Caribbean but nowhere else. The underlying reason has also been one of the findings of the 
aforementioned DEval evaluation ${ }^{122}$ : There is not enough knowledge about the instrument itself within our institutions. That is why all these myths remain present in people's minds.

I think one of the biggest bottlenecks is the fact that we do not invest sufficiently. We do not have enough resources for the modality in terms of funds because, as Nadine has just mentioned, most of the time, the German funds invested in triangular cooperation also come from the bilateral development cooperation. This means that people have to decide whether to put funds into bilateral projects which they know very well or try to invest them in triangular programmes.

The other bottleneck has to do with staff. If you do not have the experts, especially working in the field, who really know the modality and how to handle it, things are, in fact, difficult to realise. The time factor is also quite important. Most of our triangular projects have got a very short duration, maybe one year only, and if you think about all the time needed to initiate a project, this does not add up in the end and makes it very difficult. Most of the time, the project volume is very tiny, too. So, talking about efficiency or high transaction costs: with a small project volume, efficiency cannot be very good because the budget does not allow you to work for three years or more, which would be needed to have a bigger impact.

With regard to our perspectives, I would agree with what we have just heard: BAPA +40 is a big milestone for us. The DEval evaluation also gives us advice and recommendations on how to push forward the agenda on the modality. Of course, within the OECD and other international organisations, there are many interesting publications and the definition of triangular cooperation has been updated. I also think, as Orria has said, that we should look at the broader picture. If you only see South-South and triangular cooperation as an isolated issue and you do not consider the broader perspective of financing for development, of the graduation discussion, of the transition finance discussion, you cannot mainstream the modality. The strategic documents we have nowadays can really allow us to continue and consolidate the instrument in a broader picture.

Let us continue with a 'beyond-ODA' perspective. Are South-South and triangular cooperation suitable instruments for countries on their way towards or past graduation, even suitable alternatives to technical cooperation and knowledge-exchange with countries from the North? This is also interesting from another perspective, as things are changing in bilateral cooperation. Germany, for example, is currently discussing reducing the number of its partner

122 Soon to be published in English and Spanish, see https://deval.org/en/evaluationof-the-dc-modality-triangular-cooperation.html (15.04.2020). 
countries in development cooperation. Similar things are happening in other countries like Australia, the United Kingdom and the United States. The number of direct bilateral partners is shrinking, and, at the same time, there is a process of graduating from ODA for a range of countries.

Nadine Piefer-Söyler: I would say yes and no. Yes, it is suitable for thinking about ODA graduation. And no, it is not an alternative. The one word I would really take out of this question is "alternative" because I think it is not either/or; all modalities are complementary. However, triangular cooperation is more than just about maintaining relations with countries that are graduating.

I will come back to your question again but allow me to make some comments on graduation from the OECD perspective, referring to what you said in the introduction that in 2014, 29 countries were projected to graduate. ${ }^{123} \mathrm{In}$ 2014 and in the following consecutive years, the OECD came up with projections of countries that are likely to graduate until the year 2030. In these projections, 29 countries were considered, but that is by no means an indication that those 29 countries will in fact graduate. The DAC revises the list every three years (last in 2017 with the new revision taking place in 2020). Countries that have exceeded the high-income threshold, meaning that their GNI per capita remains at high-income level (above USD 12,375), for three consecutive years at the time of the review are removed. The countries that have graduated since that 2014-projection, and until March 2020, are Chile, Uruguay, the Seychelles and Cook Islands. Cook Islands was decided on during a special review that took place in July 2019, because of doubts about the reliability of the data delivered through the national statistical system. Antigua and Barbuda did not graduate, not because they were not on the high-income path for three years, but because Hurricane Irma almost completely destroyed the island of Barbuda. The heavy impact of Hurricane Irma on the Caribbean and the case of Antigua and Barbuda triggered another discussion in the DAC on re-insertion of countries to the DAC List. With that, the discussion on ODA graduation became broader and more global, moving beyond the Latin American and Caribbean region.

Coming back to South-South and triangular cooperation as an instrument in that stage of transition: as a reaction to the graduation process, we have seen that countries, especially in Latin America and the Caribbean, are already engaging more in triangular cooperation. At the same time, some DAC members are using triangular cooperation as a way of continuing to work with countries that have been taken off the list of countries eligible for ODA. Giving an example of a DAC member that is a champion on triangular cooperation, the EU, of

123 Nadine refers to the oral introduction to the group dialogue in which the projection by the OECD was mentioned. See introduction of this book. 
course, comes in as a big player. It has set up a facility for Development in Transition as well as the EU-LAC Facility for Triangular Cooperation (ADELANTE). The first phase of ADELANTE has just been concluded; the second phase is being planned and is agreed by the European Commission.

There are opportunities for DAC members to use triangular cooperation as a modality to partner with key development providers like China, India, Brazil, South Africa, and DAC members are doing that. However, it is not about replacing ODA relations, but rather about building new ways to partner among providers of development cooperation. That is beneficial, because now triangular cooperation is being pulled out of the niche that Rita also described, and it is becoming more prominent and visible.

My concern would be to talk about triangular cooperation as an alternative or seeing it as something that is only for graduating countries. Of course, it is a good option and these countries are well-placed as partners: they have structures in place, and they have often already worked in triangular cooperation. If you look at Chile and Uruguay, both are countries with a very long tradition and a lot of experience, so, of course, it seems like the perfect match. But I would also say, let us not discuss it in that area only but go beyond that.

Martin Rivero: I will begin with a couple of points still related to the previous question on challenges. First, just for the recording, most of the Ibero-American countries do not accept that category of 'graduation'. We have been discussing this a lot with the EU, OECD and with the traditional donors and we still think that is not the best way to proceed in terms of cooperation. Graduation - and then what? This is a reality, obviously, but I just want to make the political point that as SEGIB we do not accept that category. Particularly, and I think that we have seen that very strongly, when you graduate a country, you lose political dialogue with that country. And there are at least three important global issues that, in order to move forward, this dialogue prove to be extremely important. One has to do with migration: you need to have a good geostrategic dialogue with certain countries for migration issues, and that generally has nothing to do with the income level of that country. Another is the environment, particularly related to prevention and respond to natural disasters: any regional cooperation policy about the environment should include countries that are at higher level of income than the graduation level. And the same applies to health as a regional or global public good, given the transnational spread of epidemic diseases in our globalised world, like currently the new coronavirus, policies related to health are obviously global.

Second, within South-South and triangular cooperation, there are still important challenges regarding on how to work with civil society as well as there is still not so much capacity, dialogue, knowledge and funds related to develop South-South cooperation among local governments, particularly big cities, 
which are an extremely important actor in the SDG agenda. So, this is still a weak area of South-South cooperation and that affects triangular cooperation as well.

The third challenge, and related to that, is the capacity of South-South cooperation to work with vulnerable populations. If you analyse the content of South-South cooperation, at least in the Latin American region, the proportion of projects focused on the black population, the indigenous population, the handicapped population, any type of population with high vulnerability levels, is an extremely low proportion. Less than one or two per cent of all SSC projects carried out in the region during the last decade (a huge amount of around 8.000 initiatives) are focused on these populations. So, these are challenges facing South-South cooperation, and if these elements are weak in South-South cooperation, they will be weak in triangular cooperation too. Evidence started to show an important proportion of the success stories in triangular cooperation are built on previous successful South-South cooperation projects.

Finally, about that, an important difference between triangular cooperation and South-South cooperation is that in South-South cooperation you are supposed to have a common definition between the actors involved (southern countries) about the type of cooperation you are going to engage in, the principles that rule the relationship and how you will report and collect data or figures. This has some weak areas, like everything, but it exists and is legitimate for all the southern partners. If we want to work harder and more strongly, with an increasing number of projects on triangular cooperation, both sides, the 'traditional North' and the 'traditional South', will have to build together a common definition of triangular cooperation. And that has not yet been completely accepted by all the parties. What is triangular cooperation for you, Germany, for you, Japan, and for me, Guatemala, Brazil or Colombia? How will we measure it? What are the principles that rule it? And this applies to both sides. Sometimes the South says: yes, let us engage in triangular cooperation, but with my rules. But if you really want to engage in horizontal triangular cooperation, horizontal means horizontal, equal; you are not more than me and I am not more than you, so I have to accept your necessities and we have to find our common rules. This still needs to be improved, to be built between the North and the South: the rules and principles and the way of measuring the triangular cooperation that we have.

How suitable is this type of cooperation in terms of technical cooperation and knowledge-exchange? I think that the SDG agenda is an excellent framework for all of that; Nadine and the rest have been talking about an improvement in the process since the BAPA +40 conference. As of now, we have said "this is our agenda, the SDGs, these are our procedures", and we have a lot of elements to generate our future agenda on South-South and triangular 
cooperation. There is still a lot of room for improvement in certain areas, but based on the evidence we have, we are very confident that triangular and SouthSouth cooperation is quite suitable, useful and capable of finding powerful results in this 2030 Agenda. I think the answer to your question would be: yes, considering these weaknesses that we have to improve and these new political agreements that we have to achieve, it is a suitable instrument in a 'beyondODA' landscape.

This is quite interesting because you mentioned the relation between our topic, South-South or triangular cooperation, with Goal 17 on global partnerships within the SDGs. And this has both not to do and to do with graduation processes - it is the new way we are doing our work together. From our side, in the North, it is quite difficult: in my [Christof Kersting] previous job, I was in charge of a global programme on social protection. And the problem was we were excluded when we talked about South-South cooperation on social protection, because the North was not part of it, even though a lot of countries were interested in the German model. We therefore continued as a global alliance and that gave us the opportunity to include the German Ministry of Labour and Social Affairs as part of the dialogue.

Are there any additions to what has been said about the role of South-South and triangular cooperation for graduating countries? Let us also move on to discuss how these instruments can be further promoted, more recognised and improved. Orria, you already mentioned it is important for the African context to have more of these modalities within this internationally agreed new development agenda, and Rita is also trying to push the discussion forward within BMZ, to also promote what has been established and evaluated in Latin American countries for African and Asian contexts.

Orria Goni: I very much agree with Nadine - it is not an alternative, but an additional and complementary modality and we really need to think that way. In this precise same way of thinking, the financing for development agenda had seven pillars that we were looking into. This SSC/TrC agenda is about means of implementation, which brings us back to the SDG 17 - to strengthen the means of implementation and revitalize the global partnership for sustainable development. SSC and TrC are both complementary means to implement national development priorities that are aligned with the SDGs. We need to put this comprehensive perspective into the game.

Regarding the question about how SSC can be further promoted, my response here is linked to the current challenges we face in this agenda. In the case of the African continent - being either a middle-income country, a graduating country or a least-developed country - , and their means of implementation to achieve their own national development priorities: we have seen (and this is also a legacy of the development effectiveness agenda), that the starting 
point is both strong national ownership and leadership. This means strong ownership that promotes alignment with a country's national development priorities. And this is what we are currently helping with in UNDP, with Botswana and now Cabo Verde: to make sure that countries have longer-term goals when they design South-South cooperation agendas, through their own national SSC strategies. For example, Cabo Verde is now in the process of developing a national South-South strategy that is aligned with its national development strategy, and it is not just something ad hoc with no clear contribution to the SDGoriented priorities. Secondly, at UNDP we believe that in order to further promote SSC and $\operatorname{TrC}$, we need to reinforce that coordination and coherence on the SSC and TrC-related work and initiatives, by setting up coordination mechanisms - in the format of an SSC Unit, for example. This is, in the same way that countries are establishing an SDG coordination platform for monitoring and evaluation, connecting also how bilateral partners and other financing flows are contributing to national development priorities. A third element, connected to this national coordinating structure for SSC, is the idea of a system that can track those partnerships and that can tell us where this partnership is taking us in terms of the planned national targets, and that it is not an isolated projectdriven or programme-driven only. This is a process where we have been providing support to countries like Uganda and Ethiopia, mapping out the SSC activities from the different ministers to ensure there is a tracking system of where they are leading the country to. From our understanding in UNDP, these aspects - the idea of a national strategy, the establishment of a SSC unit that coordinates the work and the idea of a system that tracks what happens in terms of southsouth cooperation - are some key elements, very much aligned to what BAPA +40 indicated regarding institutional capacity and the whole set-up to make South-South cooperation happen at national level. All this lies in the intention to become an active South-South partner, but I can also become an active South-South host country, to ensure that there is alignment and that it does not come here and there, and I do not even know when it will happen or where it will happen.

One important additional element to consider for further promoting SSC, very much related to what Martin was saying, is the need to have inclusive multi-stakeholder partnerships that are developed in South-South national architecture settings. We know that trade unions are doing exchanges with other trade unions or universities with other universities, and we know that SouthSouth exchanges are happening at a decentralised level. So, we need to make sure that they are all part of the national and regional dialogue, so that we can ensure proper coherence and coordination with the aim of boosting the results of SSC and TrC efforts. In my view, in the case of Africa and the AU's agenda, it is important to strengthen the regional systems and mechanisms that can 
contribute to creating coherence among different national, regional, inter-regional and global agendas. In Africa, the clear entry point should be through the AUDA-NEPAD.

So, let me just summarise by saying: in order to further promote SSC and $\operatorname{TrC}$, particularly in Africa, there needs to be institutional capacity-building, at the planning level, at the monitoring level, but also system-wise. This means creating platforms and creating systems for national and regional dialogue around SSC for tracking and monitoring those partnerships.

The last point will be: if we want these horizontal partnerships to happen, if we want this knowledge transfer to happen, we need to create the space for them, and we need to start getting on board. It is not enough with one report prepared by the North on good practices, or a good development solution that these countries are preparing or are eager to share. Our colleagues from the Islamic Development Bank (IsDB) are doing an amazing job mapping all these resource centres so that countries can know what they have to share to other countries. I think there is a huge need for knowledge management, for the codification and the systematisation of those good practices. And we need to do that, because otherwise, we are not promoting those countries and we are not promoting those solutions. We do have the South-South Galaxy that the UN Office of South-South Cooperation has launched ${ }^{124}$. We need to feed into that, and we need to make use of that, so that people have access to that information, so that we can channel and encourage those technical exchanges.

Rita Walraf: Let me share some more ideas on how to promote the modality. I would also start by creating an enabling environment, like the recent publications by the OECD ${ }^{125}$ and by the IsDB and the South Centre ${ }^{126}$ have been confirming. I think this is key in terms of what you have just mentioned: capacitybuilding, not only for southern partners, for their incoming and outgoing aid, but also talking about the DAC members themselves. We need these elements in terms of awareness but also institutionally speaking to create such an enabling environment. Secondly, information campaigns may also be mainstreamed within partner and donor institutions, and we need to continue to share the evidence and good practices that have been produced, like the South-South Galaxy tool. For example, I have already mentioned the evaluation of the German DEval Institute on the instrument with 16 case studies, and we are working on a plan to disseminate the findings and recommendations. We are collecting good practice examples to share with the international community. And yes, we also need more resources, although this is not a popular demand.

124 See spotlight viii on the UN South-South Galaxy in this publication.

125 OECD 2019f.

126 Islamic Development Bank/South Centre 2019. 
Let us come to the last part of our discussion and go a bit more deeply into the role of new donors and their agendas. Moreover, in terms of final conclusions, let us come back to the key question of the future of international development cooperation - do you dare to offer an outlook and some recommendations on South-South and triangular cooperation in the short and medium terms? Nadine Piefer-Söyler: Generally, we work with many providers of development cooperation beyond the DAC membership and we have forms and mechanisms of support. For example, together with the Islamic Development Bank, we focus on strengthening institutions or institutional capacities, making capacity assessments of countries that are interested in and also benefitting from the experience of DAC members. One point that I think is often neglected in global discussions is that the DAC itself is extremely heterogeneous. Many newer DAC members and participants have gone through very similar processes or faced the same challenges as some of the emerging partners in development cooperation.

The DAC went through a reform process in 2017: its vision is 'to influence and to be influenced'. And I think we need this openness on both sides to link the two communities. The internal discussion that we often hear on the DAC side is, of course, still: how do we uphold our standards? This is a very legitimate discussion, and that is what the DAC was created for and these standards and experiences can be insightful for partners beyond its membership. At the same time, experiences of providers of South-South cooperation could be inspiring for DAC members as well.

Nevertheless, we need to bear in mind discussions in the South-South cooperation community which, also of course justified through historical experience, would not necessarily want to include the North in discussions on SouthSouth cooperation. To start breaking up the North-South and South-South divides, we would need to talk about international cooperation or international partnerships for development. But for that to happen, I think we need both sides to enter more into dialogue with each other. In any field of this kind of cooperation, there are a lot of myths, misperceptions and misunderstandings, so we need more dialogue to really understand where we all come from, and what our priorities for going forward and our commonalities are.

Orria Goni: We need to think of setting up new partnerships. We know that there are new providers, there are new donors, there are countries that want to become new donors, that want to become active South-South partners through different means, either by contributing to the UN but also by being an active OECD partner and, at the same time, by being active in other platforms as well. The future of development cooperation is here and is very different, completely 
different to the MDG days or even the Logical Framework Approach days ${ }^{127}$, and we need to think of new financing instruments to make that happen. And when we talk about transaction costs, we need to think that we are going to deal with transaction costs anyway because that is what it takes when you form a partnership.

But what we need to underline is: let us make things bigger, lets scale up and let us bring more partners on board for greater impact. This will promote the principle of SSC to create horizontal partnerships, making it a win-win situation for everyone. But we should also be thinking of bringing in private actors. In this regard, we need to think of being ready and supporting our member countries to be ready to set up - and manage - an SDG oriented bond; we also need to think of how to establish guarantees, how to partner with multilateral development banks and how to create all the bankable projects that everybody is talking about. The OECD is preparing a lot of countries and is working in this direction, so blended finance is the way forward, but we see that technical cooperation needs to fit there, too. Knowledge transfer needs to fit there. It is not only about financing instruments but also bringing in other elements. And it is going to be extremely demanding, of course, to set up these partnerships, but this is the world we are living in, which justifies the need to scale up our efforts. We cannot have pilots in a community anymore - these need to be nationwide, attached to ministries and then we need to make things bigger. And the way we can make things bigger is by all of us coming together. Of course, it is going to be extremely complicated, but well, this is how and why we need to get ready.

So, the whole issue of an enabling environment and looking into the regulatory frameworks of the country as well as the managerial capacities of these new partnerships is a huge agenda, at the country level, at the regional level and at the global level. The conclusion is, at least in the case of Africa: let us all contribute to make African money work for African development.

Rita Walraf: I do not want to repeat the many good recommendations you have been giving, but just let me add some points concerning the need or not of having common definitions and standards. We have been talking about this topic for ages, about the North and South and standards and principles - and, of course, it is important to somehow have common standards, the feeling of what it means to set up a project in a horizontal manner or not and also ownership. But in my view, it would not promote the modality; it would not be very positive

127 The Logical Framework Approach was developed for USAID in 1969 as a methodology for designing, monitoring and evaluating international development projects. 
to go on with the debate and go into the nitty-gritty details because we cannot lose time.

For me, our starting point is SDG 17, global partnerships for the goals, and I think it would be counterproductive to go on with that very theoretical debate. In Buenos Aires, BAPA +40 has shown that there is a way forward between the North and South, and triangular cooperation stands exactly for building bridges between the North and South. We should keep the instrument as flexible as possible to make any contribution from any side possible to achieve the SDGs, so we should focus on learning by doing together without debating too much on theories instead.

Martín Rivero: Just some thoughts: First, I personally do not much like the idea of the 'new donors'. Definitely they are not new; and generally, these countries do not like to call themselves donors, so 'new donors' is a category that sometimes makes 'noise' so perhaps is not very good one.

Second, we are closer than ever before to achieve common ground in terms of thinking about these issues. I mean, as SEGIB we have accumulated the information of 22 countries for more than 10 years, if you add the accumulation of OECD and the recent work of UNDP in Africa we have encounters with more than 80-90 countries together, so that is a lot of countries on which to collect the evidence, the experiences and the knowledge of what has happened. Unfortunately, we still do not have the political consensus to decide all these countries together, but nowadays we are closer to having a better dialogue and this meeting is an example of that, so thank you, Juliane and Christof and everybody, for organising this type of discussion. So, in a certain way, I am positive about how we are moving forward to get together and to think bigger, as Orria was saying.

Third, we are in quite a strange political context. The development cooperation discussions inside the countries are not in the top priority and budgetary position, which is something that we must accept. Even in countries that have long experience of supporting development cooperation, for example in the country I am staying now, Spain, development cooperation is not set very high on the national agenda. This is a problem. And now, there is great uncertainty about the impact of Brexit. I really do not know what is going to happen, but Britain has been putting a lot of money into development cooperation, even when those budgets were going down in other countries. So, they will differentiate their strategy compared to the European Union and perhaps this moment of lack of clarity is an opportunity to think out of the box. I think this negative political context outside the development cooperation community is also pulling us closer together and I think we are closer to finding common ground that was much more difficult to find before. That said, I am confident that we can build together these new positions and that is why I congratulate you again on 


\section{Dialogue 7}

conducting this project. It is extremely important to continue generating the knowledge and evidence that helps us to find a common position on these issues. 